\title{
Tracheal Lipoma Mimicking Asthma
}

Barıș Çil, MD ${ }^{1 *}$; Mehmet Kabak, MD ${ }^{1}$

'Department of Chest Disease, Mardin Training and Research Hospital, Mardin, Turkey

\begin{abstract}
Primary tracheal tumors are very rare and $10 \%-20 \%$ are benign tumors. Tracheal lipoma is extremely rare and only a few cases have been reported in the literature. A 69-year-old male patient presented to the emergency department with complaints of shortness of breath, respiratory distress, chest pain and cough. Chest CT scan showed a round mass in the topography of the trachea that almost caused airway obstruction. The lesion was resected endoscopically and the pedicle base was cauterized. Tracheal lipoma is a rare condition that should lie in the differential diagnosis of treatment-resistant asthma.

Keywords: Asthma, Bronchoscopy, Cough, Tracheal lipoma

Cite this article as: Çil B, Kabak M. Tracheal lipoma mimicking asthma. Arch Iran Med. 2021;24(12):916-918. doi: 10.34172/ aim.2021.137
\end{abstract}

Received: October 18, 2020, Accepted: March 9, 2021, ePublished: December 1, 2021

\section{Introduction}

Tumors that originate from the trachea are very rare and few of them are benign tumors (10\%-20\%). The main benign tumors are chondroma, papilloma, fibroma and hemangioma. Tracheal lipoma, which is one of the benign tumors of the trachea, is rarely encountered in the literature. ${ }^{1.5}$

If we evaluate the symptoms of this tumor, we may see nonspecific symptoms such as dry cough and wheezing, and rarely respiratory failure. Obstructive pulmonary diseases may be considered in the diagnosis due to these symptoms. These patients do not respond to the given treatment. In case of insufficient response to treatment, evaluation with fiberoptic bronchoscopy should be performed. Resection is required in any tumoral obstruction and can be achieved by both endoscopic and open surgery. ${ }^{1-4}$

We report a case of an elderly male with tracheal lipoma following bilateral pneumonia and respiratory failure while he was in the intensive care unit without any previous response to asthma treatment.

\section{Case Report}

Our case is a 69-year-old male. He was admitted to the emergency room with dyspnea, respiratory distress, chest pain and cough. He reported the worsening of his complaints over the past week. Over the past year, he experienced periods of dry cough, wheezing and shortness of breath. During this period, the patient was treated with bronchodilators, inhaled corticosteroids and oral corticosteroids and responded partially. He was treated as an outpatient for recurrent pulmonary infections. There was no additional disease.

Physical examination revealed fever, tachypnea, tachycardia, hypotension, respiratory distress, wheezing, stridor, decreased lung sounds on the basis of lung, and $81 \% \mathrm{SpO}_{2}$, although additional oxygen was injected through the nasal cannula $(7 \mathrm{~L} / \mathrm{min})$.

Onthe chest X-ray of the patient, there were areas of lung hyperinflation and alveolar consolidation in the lower half of both pulmonary fields. The patient was admitted to the intensive care unit due to pneumonia and respiratory failure, and noninvasive mechanical ventilation support was provided.

On the chest CT scan of the patient, there were bilateral alveolar consolidations in the lower lobes. Also, a round mass causing almost complete airway obstruction was seen in the topography of the trachea (Figure 1).

If the physician does not have clinical and radiological suspicion, tracheal tumors can be missed. We performed fiberoptic bronchoscopy for our patient, and confirmed the presence of a single-stemmed mobile lesion on fiberoptic bronchoscopy. This lesion caused occlusion of approximately $90 \%$ of the tracheal lumen and had a smooth surface (Figure 2). The lesion was endoscopically resected with the aid of a polypectomy snare, and the base of the pedicle was cauterized. On pathological examination of the material, histological findings compatible with lipoma were observed (Figure 3).

After bronchoscopic surgery and cryotherapy, the upper airway was completely cleared. The patient recovered clinically and radiologically and was discharged on the 18 th day.

\section{Discussion}

Tumors originating from the trachea are very rare. Tracheal tumors are mostly malignant. Papillomatous polyps are the most common benign tumors. However, chondromas, leiomyomas, adenomas, hamartomas, neurofibromas, hemangiomas, glomus tumors and 


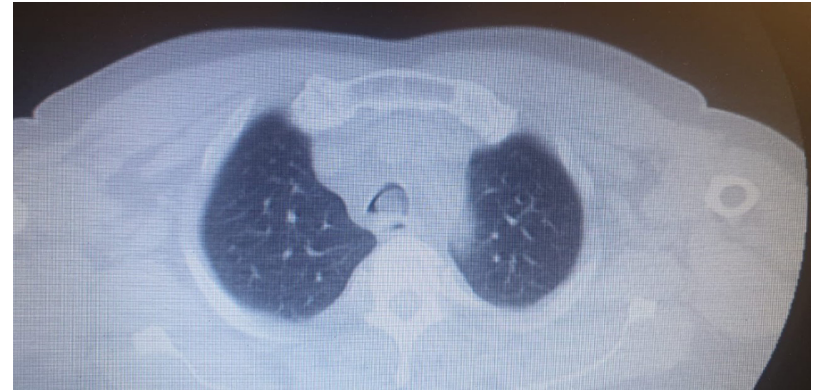

Figure 1. On the patient's chest $C T$, in the topography of the trachea, a round mass occluding almost all of the tracheal lumen was observed.

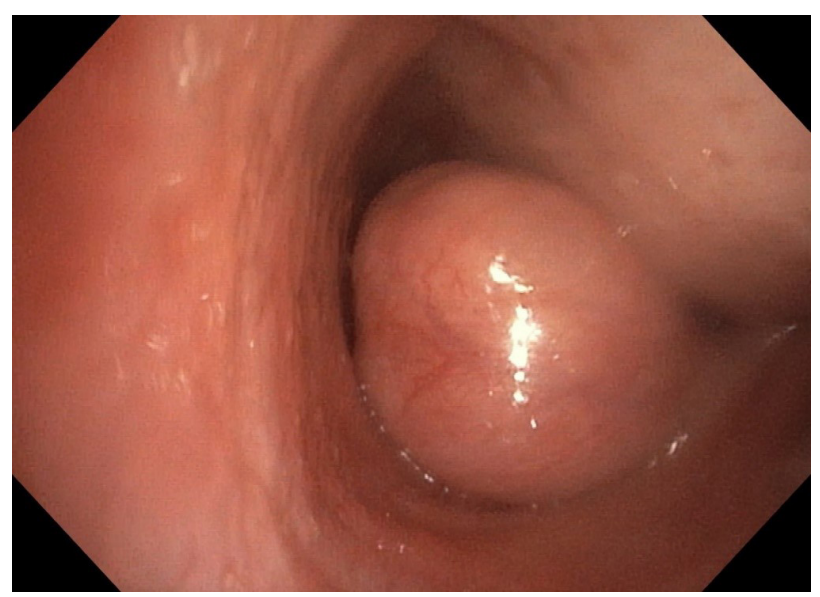

Figure 2. Mobile lesion with a single stalk implanted in the left lateral wall of the distal trachea and almost completely occluding the lumen.

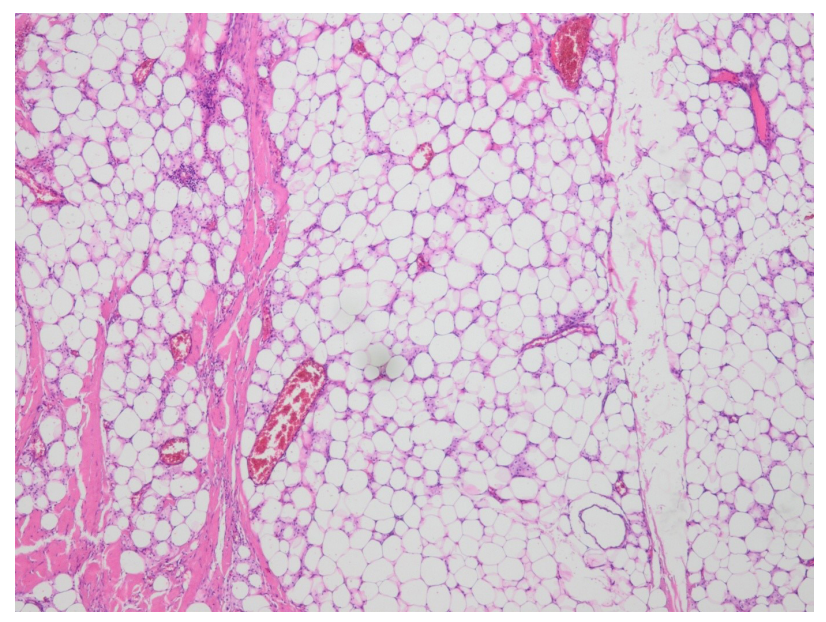

Figure 3. On examination of the sections, fibrous bands and vascular structures were observed in the mature adipose tissue. These findings are consistent with lipoma (H\&E staining, $\times 20)$.

lipomas are rarely seen. Lipomas account for $0.1-0.5 \%$ of all pulmonary tumors and are more common in the endobronchial area. ${ }^{5-7}$ Tracheal lipoma is very rare. The lower third of the trachea is where benign tracheal tumors are usually located. However, the statistical data reporting its incidence could not be determined in the literature. ${ }^{8,9}$ In a case series from Japan, 64 cases of endobronchial lipoma were reported. ${ }^{10}$ Also, studies have reported cases of tracheal lipoma in Taiwan and Brazil., ${ }^{2,4}$

Tracheal lipoma is more common in middle-aged men. ${ }^{11}$ Symptoms occur when the lumen is narrowed. It is manifested by dry cough, wheezing, shortness of breath and stridor. Generally, their clinical appearance mimics obstructive pulmonary diseases such as asthma and chronic obstructive pulmonary disease, leading to a delay in diagnosis and treatment errors. ${ }^{7}$ Sometimes, other diseases can mimic the clinical profile of asthma: (1) In anterior pedicled tracheal tumors, worsening of dyspnea in the supine position may be confused with nocturnal asthma; (2) finding of a hyperinflated lung on chest X-rays in cases of tumors that have a ball-valve effect; and (3) short-term improvement after the use of oral corticosteroids, caused by the reduction of the edema surrounding the tumor. ${ }^{4}$ In our case, the patient had received asthma treatment for about 1 year.

Radiologically, the chest $\mathrm{x}$-ray is usually normal, but hyperinflation may occur because the tumor closes the trachea almost completely. Chest computed tomography and magnetic resonance imaging are necessary for diagnostic evaluation of tracheal lipoma. These imaging methods provide insight into the location, extent and invasion of the endotracheal lesion to other paratracheal tissues. ${ }^{12}$ In our case, previous chest radiographs were normal and the lesion was detected on chest computed tomography.

The most important and diagnostic examination in the diagnosis of tracheal lipoma is flexible bronchoscopy. Lipoma in the tracheobronchial tree is seen as a glossy, lobulated, stalked or broad-base fatty submucosal growth. Preoperative biopsy with flexible bronchoscopy is controversial because of the risk of bleeding, lumen closure and aspiration. ${ }^{1} \quad$ Necessary preoperative histological diagnosis is controversial. Some authors do not recommend it because of complications. In addition, bronchoscopic biopsies taken from the tracheal lipoma capsule may cause misdiagnosis. In our view, we are considering the use of endobronchial resection and cryotherapy due to progressive advances in bronchoscopy. It is necessary both for the improvement of the symptoms and for the correct diagnosis by removing the tumor tissue completely.

Treatment for tracheal lipoma is the excision of lipoma by bronchoscopy, or in some cases, tracheal resection with end-to-end anastomosis. Laser treatment with flexible or rigid bronchoscopy, cryotherapy or argon plasma coagulation is now being used more frequently. It is used more frequently due to both ease of procedure and fewer complications. The technique to choose should be left to the experience and preference of the operator. No recurrence has been reported after bronchoscopic procedures in the literature. Tracheal resection and reconstruction have been applied in these rare tracheal lipoma cases. Approximately $5 \%$ of patients undergoing tracheal resection require tracheostomy or advanced surgical procedures to treat postoperative tracheal stenosis or anastomotic dissociation. Therefore, surgical resection should be performed only in selected cases. ${ }^{1-13}$ 
In our case, endobronchial resection and cryotherapy were performed. The patient was discharged on the 18th day without any complication.

Tracheal lipoma and other tracheal tumors should be considered in cases of unresponsive asthma and chronic bronchitis. Bronchoscopic procedures are the most effective and safe treatment of tracheal lipoma. It should be recommended as the first approach in the diagnosis and treatment of tracheal tumors. Tracheal resection and reconstruction should only be considered in selected cases when considered histopathologically malignant or when invasion into paratracheal tissues on radiological imaging is considered and endoscopic treatment fails.

\section{Authors' Contribution}

BC: Patient's followed up and treatment, contributing in paper writing. MK: Paricipating in the paper writing.

\section{Conflict of Interest Disclosures}

There is not any conflict of interest.

\section{Ethical Statement}

An informed consent was signed by the patient.

\section{References}

1. Rotolo N, Cattoni M, La Rosa S, Imperatori A. A rare case of incidental tracheal lipoma. Arch Bronconeumol (Engl Ed). 2018;54(12):630-2. doi: 10.1016/j.arbres.2018.02.023.

2. Wu BR, Chen $\mathrm{CH}$, Liao WC, Cheng WC. Life-threatening tracheal benign tumor: lipoma. Intern Med. 2016;55(12):16778. doi: 10.2169/internalmedicine.55.6334.

3. Nassiri AH, Dutau H, Breen D, Colchen A, Quiot JJ, Nguyen B, et al. A multicenter retrospective study investigating the role of interventional bronchoscopic techniques in the management of endobronchial lipomas. Respiration. 2008;75(1):79-84. doi: 10.1159/000109709.

4. Mota VT, Maia JG, Barbosa AT, Fernandes DF, Rocha EB. Tracheal lipoma mimicking obstructive lung disease. J Bras Pneumol. 2010;36(1):152-5. doi: 10.1590/s180637132010000100021.

5. Caiado A, Moura e Sá J. [Tracheal tumors review--a clinical case of adenoid cystic carcinoma]. Rev Port Pneumol. 2008;14(4):527-34. doi: 10.1016/s0873-2159(15)30257-9. [Portuguese].

6. Gamblin TC, Farmer LA, Dean RJ, Bradley RA, Dalton ML. Tracheal polyp. Ann Thorac Surg. 2002;73(4):1286-7. doi: 10.1016/s0003-4975(01)03115-0.

7. Baldi BG, Fernandes CJ, Salge JM, Takagaki TY. Tracheal polyp. J Bras Pneumol. 2007;33(5):616-20. doi: 10.1590/s180637132007000500020.

8. Bof AM, Rapoport A, Paier LC, Diaz YL, Leiro LC, PandoSerrano RR, et al. Endobronchial lipoma. J Bras Pneumol. 2005;31(6):555-8. doi: 10.1590/s1806-37132005000600015.

9. Gaissert HA, Grillo HC, Shadmehr MB, Wright CD, Gokhale $\mathrm{M}$, Wain $\mathrm{JC}$, et al. Uncommon primary tracheal tumors. Ann Thorac Surg. 2006;82(1):268-72. doi: 10.1016/j. athoracsur.2006.01.065.

10. Muraoka M, Oka T, Akamine S, Nagayasu T, Iseki $M$, Suyama N, et al. Endobronchial lipoma: review of 64 cases reported in Japan. Chest. 2003;123(1):293-6. doi: 10.1378/ chest.123.1.293.

11. Morton SE, Byrd RP Jr, Fields CL, Roy TM. Tracheal lipoma: a rare intrathoracic neoplasm. South Med J. 2000;93(5):497500.

12. Ko JM, Jung Jl, Park SH, Lee $\mathrm{KY}$, Chung $\mathrm{MH}$, Ahn MI, et al. Benign tumors of the tracheobronchial tree: CT-pathologic correlation. AJR Am J Roentgenol. 2006;186(5):1304-13. doi: 10.2214/ajr.04.1893.

13. Bibas BJ, Terra RM, Oliveira Junior AL, Tamagno MF, Minamoto $\mathrm{H}$, Cardoso PF, et al. Predictors for postoperative complications after tracheal resection. Ann Thorac Surg. 2014;98(1):277-82. doi: 10.1016/j.athoracsur.2014.03.019 